\title{
A Swollen Seed Found in a Child's Ear Amidst COVID-19 Lockdown: A Case Report
}

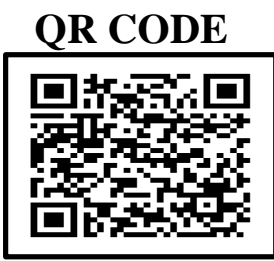

\section{POOJA PANWAR ${ }^{* 1}$, RAJEEV G. DOLE², DEVANSHU CHAUDHARY³, MANJIRI KESKAR ${ }^{4}$, SHIVKANT SHARMA}

Foreign body lodgement in external auditory canal in pediatric age group is a common problem encountered by Otolaryngologists in emergency as well as in outpatient department. A case report of swollen seed found in external auditory canal in right ear, of a 6-year-old boy out of poverty, neglect and unavailable ENT consultant OPD due to lockdown for the serious pandemic condition.

\section{KEYWORDS: External Auditory Canal, Seed, Foreign Body, Coronavirus}

\section{INTRODUCTION}

One of the most common problem an Otolaryngologist or an ENT surgeon face in the pediatric population is the presence of Foreign Body (FB) in the ear. The foreign body varies its profile and can be classified as animate and inanimate foreign body. The inanimate foreign bodies are further classified into two groups as vegetative and non-vegetative foreign bodies, and hygroscopic and non-hygroscopic foreign body. The foreign body includes seeds, nuts, grains and others. The most common ear foreign bodies include paper, cotton wool, rubber, stones, beads, plastic toys, stones, and popcorn kernel. ${ }^{1}$ In the series of animate foreign bodies the commonly found are cockroaches and beetles and also include insects like ants, moths, flies, etc. ${ }^{2}$

These foreign bodies seek instant attention as it can lead to severe pain, anxiety, and discomfort to the patient. ${ }^{3}$ The episodes of foreign bodies are more frequently seen in children than adults, which can be characterized by certain clinical features such as otitis externa attributable to a foreign body in the external meatus which leads to deafness, tinnitus, and otalgia. The seriousness of this common problem can be understood with the detailed knowledge of complication associated with it. Beside the problem of bleeding and otitis externa the major complications in the procedure of foreign body removal are iatrogenic complication like canal laceration, bleeding, infection, and perforation of tympanic membrane.
Hence, an attempt is made with the help of this case report to highlight the incidence of a swollen seed in the external auditory canal and the complications in its line of treatment.

\section{CASE REPORT}

A 6-year-old male child presented to the emergency of Saksham Hospital, Saharanpur (U.P) with his grandmother and Pradhan of village with a complaint of pain and fullness in right ear. On examination the condition was diagnosed as Otalgia, which is turning to be severe and has been progressive for about 1 week. There was pain or ache and feeling of fullness of the affected ear. His parents stated that they tried some home remedies such as oil pulling in affected ear at home and also some chandelier tried for affected ear due to unavailability of medical facility in lockdown. The Otalgia and discomfort of child is so much severe that it gains the attention of village Pradhan, who brought him to the random Clinic in Saharanpur where he was referred to the ENT OPD of Saksham Hospital. The family was facing poverty and illiteracy due to which they found it difficult to seek proper treatment to the child. His father is a farmer and mother house wife.

On examination: The child was afebrile, not pale and anicteric. His temperature was $37^{\circ} \mathrm{C}$, pulse rate 97 beats $/ \mathrm{min}$ and weight $28 \mathrm{~kg}$. On examining the ears with otoscope, the left ear was essentially normal. In the right ear there was preauricular and 
post auricular tenderness. The external auditory canal was edematous and congestion present. The tympanic membrane (TM) was normal. Rhinne test was positive in the right ear and negative in left ear. Weber test lateralized to the right ear. Pure tone audiometry was not done due to the condition of the affected ear.

The foreign body was near to posterior inferior quadrant adherent to sulcus terminalis and firstly an attempt was made with hert'sman forcep and Jobson's probe to remove but its failed then it's removed by syringing with Luke warm water with savlon and it's turned out to be a swollen seed (Figure 1). Repeat otoscopy revealed the TM was intact, dull and mild congestion present. The EAC also appeared oedematous and mild lacerated especially around the area of seed impacted. The EAC was further cleaned and mobbing done. Tuning fork test repeated without any change in the result. Patient was given oral antibiotics and analgesics, and appointment given for follow up. He however did not show up again.



Figure 1. Swollen Seed removed from the Child's ear.

\section{DISCUSSION}

The cause of foreign bodies in nose or ear has been recognized to the broad-spectrum inquisitiveness and a urge to explore orifices in children, playful insertion of foreign bodies into others' body parts, accidental entry of foreign body, pre-existing disease in ear causing irritation, habitual cleaning of ear and nose with objects like ear buds. ${ }^{4}$ It was once thought that the tendency of a few children to inflict foreign body upon self or others is a kind of childish attitude. A significant morbidity can occur due to the presence of foreign body in the ear and may be due to the small anatomic size and gentle skin of the EAM and the thinness of the tympanic membrane. ${ }^{1,5}$ In case of vegetable foreign bodies if left untreated, break down to release irritant vegetable oil and leads to inflammation. The condition can even turn out to be worst if the foreign body gets swollen and later it can be sprouted. Some of the common reason behind this is neglect, and deceptive show by the parents due to poverty and ignorance. In this case poverty, lack of knowledge, and unavailability of proper medical care due to lock down can leads to such complications. But with the efforts of child's parents and Pradhan we pull out the seed before germination and further complications. The cases of unusual foreign body in ear have been reported but the case of swollen seed or germinated seed are rare. ${ }^{6,7}$ Hence, an attempt has been made to describe the case of swollen seed and its complications in a tough time of severe pandemic situation

\section{CONCLUSION}

We conclude that the case of swollen seed in the ear is an unusual clinical situation. Poverty, illiteracy, and a severe pandemic condition make it difficult to seek better health care delivery in our environment. Focus should be on strengthening the health care delivery system for the needy population even in the severe pandemic conditions and low economic budget families.

\section{REFERENCE}

1. Ansley JF, Cunningham MJ. Treatment of aural foreign bodies in children. Pediatrics 1998; 101(4): 638-41. http://dx.doi.org/10.1542/peds.101.4.638

2. Sarkar S, Roychoudhury A, Roychaudhuri BK. Foreign bodies in ENT in a teaching hospital in Eastern India. Indian J Otolaryngol Head Neck Surg. 2010; 62(2): 118-20.

http://dx.doi.org/10.1007/s12070-010-0040-6

3. Bressler K, Shelton C. Ear foreign body removal:

a review of 98 consecutive cases. Laryngoscope 1993; 103: 367-70. http://dx.doi.org/10.1002/lary.5541030401

4. Das SK. Aetiological evaluation of foreign bodies in the ear and nose. J Laryngol Otol. 1984; 98: 989-91.

http://dx.doi.org/10.1017/Soo2221510014784X

5. Ijaduola GT, Okewo PA. Foreign body in the ear and its importance; the Nigerian experience. J Trop Pediatr. 1986; 32:4-6.

http://dx.doi.org/10.1093/tropej/32.1.4

6. DiMuzio J Jr, Deschler DG. Emmergency department management of foreign bodies of the 
external ear canal in children. Otol Neurotol. 2002; 23:473-5. http://dx.doi.org/10.1097/o0129492200207000-00014

7. Cimolai N, Cimolai TL. Otitis from the common bedbug. The Journal of Clinical and Aesthetic Dermatology 2012;5(12):43-5 .

8. Bala A, Purushotman R, Lina LC, Avatar S. Superglue Accidentally Used As Ear drops. Med J Malaysia. 2012;67(2); 212-13.

9. Arora S, Goyal SK. Unusual foreign body in the ear in an adult with psychiatric illness. Indian Journal of Psychiatry. 2009;51(2):164. http://dx.doi.org/10.4103/oo19-5545.49467

10. Schulze SL, Kerschner J, Beste D. Pediatric external auditory canal foreign bodies: a review of
698 cases. Otolaryngol Head Neck Surg. 2002;127(1):73-8.

http://dx.doi.org/ 10.1067/mhn.2002.126724.

11. Phillips JJ, Patil P. Swallowed foreign bodies. J Laryngol Otol. 1988;102:235-41.

12. Balbani AP, Sanchez TG., Butugan O., et al. Ear and nose foreign body removal in children. Int $\mathrm{J}$ Pediatr Otorhinolaryngol. 1998;46(1-2):37-42. doi: 10.1016/So165-5876(98)oo118-9.

13. Davies PH, Benger JR. Foreign bodies in the nose and ear: a review of techniques for removal in the emergency department. J Accid Emerg Med. 2000;17(2):91-4.

Source of support: Nil, Conflict of interest: None declared

Cite this article as:

Panwar P, Dole RG, Chaudhary D, Keskar M, Sharma S. A Swollen Seed Found in a Child's

Ear Amidst Covid-19 Lockdown: A Case Report. Int Healthc Res J. 2020;4(6):148-150. https://doi.org/10.26440/IHRJ/0406.09242

\section{AUTHOR AFFILIATIONS: (*: Corresponding Author)}

BAMS, PG Scholar, Department of Shalakya Tantra, Parul Institute of Ayurveda, Parul University, Vadodara, Gujrat

BAMS, MS, Professor and Head of Department of Shalakya Tantra, Parul Institute of Ayurveda, Parul University, Vadodara, Gujrat

BDS, MDS, Department of Public Health Dentistry, Clinician at K.S Memorial Orodental Clinic, Sharanpur, Uttar Pradesh

BAMS, MS, Ph.d, Senior Professor, Department of Shalakya Tantra, Parul Institute of Ayurved, Parul University, Vadodara, Gujrat

BAMS, MS, Assistant Professor, Department of Shalakya Tantra, Parul Institute of Ayurved, Parul University, Vadodara, Gujrat 